\title{
Suppression of PDCD4 mediated by the long non-coding RNA HOTAIR inhibits the proliferation and invasion of glioma cells
}

\author{
YONG'AN CHEN $^{1,2^{*}}$, YUSONG BIAN $^{1,2^{*}}$, SHANPENG ZHAO ${ }^{2}$, FANQIANG KONG $^{2}$ and XIN'GANG LI ${ }^{1}$ \\ ${ }^{1}$ Department of Neurosurgery, Qilu Hospital of Shandong University, Jinan, Shandong 250012; ${ }^{2}$ Emergency Centre, \\ Yantai Yuhuangding Hospital Affiliated to Qingdao University Medical College, Yantai, Shandong 264000, P.R. China
}

Received April 26, 2015; Accepted May 26, 2016

DOI: $10.3892 / \mathrm{ol} .2016 .5323$

\begin{abstract}
Programmed cell death protein 4 (PDCD4) has recently been demonstrated to be implicated in translation and transcription, and the regulation of cell growth. However, the mechanisms underlying PDCD4 function in glioma cells remain to be elucidated. The current study investigated the function and regulation of PDCD4 and the results demonstrated that the expression of PDCD4 was significantly reduced in glioma cells compared with normal cells. When PDCD4 was overexpressed in glioma cells, the proliferation rate and invasive capability of the cells greatly decreased, suggesting that PDCD4 functions as a tumor suppressor in this cell type. In addition, the histone modification status of the PDCD4 gene was analyzed, and chromatin immunoprecipitation assay identified a high density of histone 3 lysine 27 trimethylation on the promoter of PDCD4, which was associated with the long non-coding RNA, homeobox transcript antisense RNA (HOTAIR). The expression of HOTAIR was significantly increased in glioma cells compared with normal cells, and it exerted its function in a polycomb repressive complex 2-dependent manner. These results may provide novel approaches to therapeutically target PDCD4 and HOTAIR in patients with gliomas.
\end{abstract}

\section{Introduction}

Human gliomas are the most prevalent malignant neoplasms of the central nervous system, with an annual incidence of $\sim 5 / 100,000$ worldwide (1). Despite the use of aggressive surgery in combination with chemotherapy, biological therapy and radiotherapy, gliomas continue to be therapeutically

Correspondence to: Dr Xin'gang Li, Department of Neurosurgery, Qilu Hospital of Shandong University, 107 Wenhua West Road, Jinan, Shandong 250012, P.R. China

E-mail: lixingang_0407@163.com

*Contributed equally

Key words: programmed cell death protein 4, long non-coding RNA, homeobox transcript antisense RNA, glioma challenging (2). For patients with glioblastoma, the relative 5 -year survival rate is $<5 \%$ (3). Novel therapies for the treatment of glioma are warranted; recent advances in the understanding of the molecular and biological nature of this disease may facilitate the development of successful therapeutics (4).

PDCD4 protein was initially determined to be overexpressed during apoptosis, which subsequently suppresses tumorigenesis $(5,6)$. Loss of PDCD4 expression is closely associated with the progression of a number of tumors, including glioblastomas (7), and kidney, ovarian and lung cancer (8-10). Low PDCD4 expression levels correlate with poor outcomes in patients with glioblastoma multiforme (11). The frequent loss of PDCD4 in glioblastoma multiforme is partly due to epigenetic silencing secondary to 5 ' cytosine-phosphate-guanine island methylation (12), in addition to overexpression of microRNA (miRNA)-21, which targets PDCD4 mRNA for degradation (13). Although several studies have examined PDCD4 in glioma, the detailed molecular mechanisms underlying the role of PDCD4 in glioma remain poorly understood.

Long non-coding RNAs (lncRNAs) are non-protein coding transcripts longer than 200 nucleotides, which are involved in various important events, including transcriptional, epigenetic and post-transcriptional regulation $(14,15)$. A previous study profiled the lncRNA homeobox transcript antisense RNA (HOTAIR), and the results demonstrated that HOTAIR was closely correlated with poor prognosis, molecular subtype and tumor grade in patients with glioma (16). However, the details of how HOTAIR regulates tumor suppressors, including PDCD4, remain unclear.

The results of the present study demonstrated that PDCD4 functions as a tumor suppressor in glioma cells, and its downregulation is associated with a high level of histone 3 lysine 27 trimethylation (H3K27me3) at the PDCD4 promoter, a level that is mediated by HOTAIR in a polycomb repressive complex 2 (PRC2)-dependent manner.

\section{Materials and methods}

Experimental subjects. A total of 24 brain glioma tissue samples and their matched adjacent normal tissues from 24 patients obtained following surgical resection were collected from the Department of Neurosurgery, Yantai Yuhuangding Hospital Affiliated to Qingdao University Medical College (Yantai, China) between August 2010 and September 2012. Adjacent 
tissues were located $1 \mathrm{~cm}$ away from lesions. All specimens were obtained under sterile conditions during surgery, and immediately placed into Eppendorf tubes and frozen at $-80^{\circ} \mathrm{C}$. The present study was approved by the ethics committee of Shandong University (Jinan, China; approval no. 20130041). Written informed consent was obtained from all patients.

Cell preparation and culture. The human astrocyte HA cell line was purchased from ScienCell Research Laboratories (San Diego, CA, USA). The human glioma cell lines U251, U87, LN-18 and H4 were all purchased from the American Type Culture Collection (Manassas, VA, USA). All cell lines were maintained in Dulbecco's modified Eagle's medium (DMEM; GE Healthcare Life Sciences, Logan, UT, USA) supplemented with heat-inactivated $10 \%$ fetal calf serum (GE Healthcare Life Sciences), 2 mM L-glutamine and $100 \mathrm{U} / \mathrm{ml}$ penicillin/streptomycin. Cells were incubated at $37^{\circ} \mathrm{C}$ in a humidified atmosphere with $5 \% \mathrm{CO}_{2}$.

Cell transfection and RNA interference. The lentivirus for PDCD4 overexpression (Lenti-PDCD4) and the control (Lenti-Empty) were commercially constructed by Genechem Co., Ltd. (Shanghai, China). The lentivirus was packaged in HEK-293T cells and collected from the supernatant following the manufacturer's protocol. Glioma cells were infected with lentiviral particles. Cell lines stably expressing PDCD4 were established using puromycin as the selection marker.

Small interfering RNA (siRNA) targeting HOTAIR was purchased from Thermo Fisher Scientific, Inc. (Waltham, MA, USA). Cells were transfected using Lipofectamine ${ }^{\circledR} 2000$ (Thermo Fisher Scientific, Inc.) following the manufacturer's protocol.

Reverse transcriptase-quantitative polymerase chain reaction $(R T-q P C R)$. RNA was isolated from the human glioma cell lines using RNAzol $^{\circledR}$ reagent (Vigorous Biotechnology Co., Ltd., Beijing, China), according to the manufacturer's protocol. The RNA was treated with DNase $\mathrm{H}$ (Beyotime Institute of Biotechnology, Haimen, China) to remove contaminating genomic DNA. cDNA was synthesized in a $25 \mu \mathrm{l}$ reaction mixture consisting of $2 \mu \mathrm{g}$ total RNA, $1 \mu \mathrm{l}$ M-MLV Reverse Transcriptase $2 \mu \mathrm{ldNTPs}, 5 \mu \mathrm{l}$ $5 \mathrm{X}$ buffer, $1 \mu \mathrm{l}$ random primers, $0.5 \mu \mathrm{l}$ RNasin and diethylpyrocarbonate (all Promega Corporation, Madison, WI, USA). qPCR was performed using the ABI 7300 Real-Time PCR system (Applied Biosystems; Thermo Fisher Scientific, Inc.) with reagents from the $\mathrm{SYBR}^{\circledR}$ Green Real-Time PCR Master Mix (Toyobo Co., Ltd., Osaka, Japan) and the appropriate primers, which are presented in Table I. The PCR cycling conditions were as follows: $95^{\circ} \mathrm{C}$ for $15 \mathrm{~min}$, followed by 40 cycles of denaturation at $94^{\circ} \mathrm{C}$ for $15 \mathrm{sec}$, annealing at $60^{\circ} \mathrm{C}$ for $30 \mathrm{sec}$, and extension at $72^{\circ} \mathrm{C}$ for $30 \mathrm{sec}$. Relative mRNA expression levels were determined following normalization to glyceraldehyde 3-phosphate dehydrogenase (GAPDH) using the $2^{-\Delta \Delta \mathrm{Cq}}$ method (17).

Cell proliferation. Cell Counting kit-8 (CCK-8; Dojindo Molecular Technologies, Inc., Kumamoto, Japan) was used to determine cell proliferation rate according to the manufacturer's protocol at the indicated time points. Briefly, cells were seeded in 96-well plates at a density of 2,000 cells/well. Cell proliferation reagent $(10 \mu \mathrm{l})$ was added to each well, and the cells were incubated for $2 \mathrm{~h}$ at $37^{\circ} \mathrm{C}$. Cell numbers were estimated by measuring the optical density at $450 \mathrm{~nm}$. The absorbance of cell-free wells containing medium was set as zero. Data was obtained from three separate experiments and three replications were performed each time.

Cell invasion assay. Transwell chambers $(8.0 \mu \mathrm{m}$ pore size; Corning Incorporated, Corning, NY, USA) coated with Matrigel (BD Biosciences,Franklin Lakes, NJ, USA) were used to measure the invasiveness of glioma cells. In brief, $5 \times 10^{4}$ cells/well were seeded in the upper chamber in DMEM without serum, and the lower chamber contained DMEM supplemented with $10 \%$ fetal bovine serum (Gibco; Thermo Fisher Scientific, Inc.) to stimulate cell invasion. Following $48 \mathrm{~h}$ of incubation at $37^{\circ} \mathrm{C}$, cells that migrated to the bottom of the chamber insert were fixed with $3 \%$ paraformaldehyde, stained with $0.1 \%$ crystal violet, extracted with $33 \%$ acetic acid and finally detected quantitatively using a standard microplate reader (at $570 \mathrm{~nm}$ ). Data was obtained from three separate experiments and three replications were performed each time.

Western blot analysis. Protein extracts $(10 \mu \mathrm{g})$ prepared with radioimmunoprecipitation assay buffer were separated by $12 \%$ SDS-PAGE and transferred to nitrocellulose membranes by electroblotting. Subsequent to blocking with 5\% non-fat milk, the membranes were incubated overnight at $4^{\circ} \mathrm{C}$ with mouse anti-PDCD4 (\#sc-376430) and mouse anti-GAPDH (\#sc-25778) monoclonal antibodies (dilutions, 1:1,000; Santa Cruz Biotechnology, Inc., Dallas, TX, USA). Blots were then incubated with peroxidase-conjugated goat anti-mouse secondary antibodies (dilution, 1:1,000; \#ZB2305 and \#ZB2307; Beijing Zhongshan Jinqiao Biotechnology, Co., Ltd., Beijing, China) for $1 \mathrm{~h}$ at room temperature and developed using a SuperSignal ${ }^{\mathrm{TM}}$ West Pico Chemilumiscent substrate (Pierce Biotechnology, Inc., Rockford, IL, USA). Immunoblots were scanned using Image $\mathrm{Lab}^{\mathrm{TM}}$ software, version 1709690 (Bio-Rad Laboratories, Inc., Hercules, CA, USA).

Chromatin immunoprecipitation (ChIP) assay. Cells were fixed with $10 \%$ formaldehyde and sonicated to prepare the chromatin sample. Chromatin samples were immunoprecipitated with mouse anti-H3K27me3 monoclonal antibody (\#ab6002; Abcam, Cambridge, MA, USA), rabbit anti-enhancer of zeste homolog 2 (EZH2) polyclonal antibody (\#ab3748; Abcam) or rabbit immunoglobulin $\mathrm{G}$ (IgG; \#ab6785; Abcam) at $4^{\circ} \mathrm{C}$ for $3 \mathrm{~h}$. Following crosslink reversal, precipitated DNA was analyzed by PCR for fragments of the PDCD4 promoter using the following primers: Forward, 5'-GGGAGGAGGAATCGGACAG-3'; and reverse, 5'-TATGTTGGGAGGCGTGGC-3' (141 bp). The PCR cycling conditions were as follows: $95^{\circ} \mathrm{C}$ for $15 \mathrm{~min}$, followed by 40 cycles of denaturation at $94^{\circ} \mathrm{C}$ for $15 \mathrm{sec}$, annealing at $60^{\circ} \mathrm{C}$ for $30 \mathrm{sec}$, and extension at $72^{\circ} \mathrm{C}$ for $30 \mathrm{sec}$. The data obtained were normalized to those of corresponding DNA precipitated by $\operatorname{IgG}$.

Statistical analysis. All data are expressed as the mean \pm standard deviation. Comparisons between two groups were performed using Student's $t$-test or among groups 
Table I. Primer sequences for each gene.

\begin{tabular}{llc}
\hline Gene & \multicolumn{1}{c}{ Primer sequences, 5'-3' } & Product size, bp \\
\hline GAPDH & & 116 \\
Forward & TGTGGGCATCAATGGATTTGG \\
Reverse & ACACCATGTATTCCGGGTCAAT \\
PDCD4 & & 108 \\
Forward & GGGAGTGACGCCCTTAGAAG \\
Reverse & ACCTTTCTTTGGTAGTCCCCTT \\
HOTAIR & & 135 \\
Forward & GGCAGCACAGAGCAACTCTA \\
Reverse & GAGTGCAAAGTCCCGTTTG \\
\hline
\end{tabular}

GAPDH, glyceraldehyde 3-phosphate dehydrogenase; PDCD4, programmed cell death protein 4; HOTAIR, homeobox transcript antisense RNA.

A
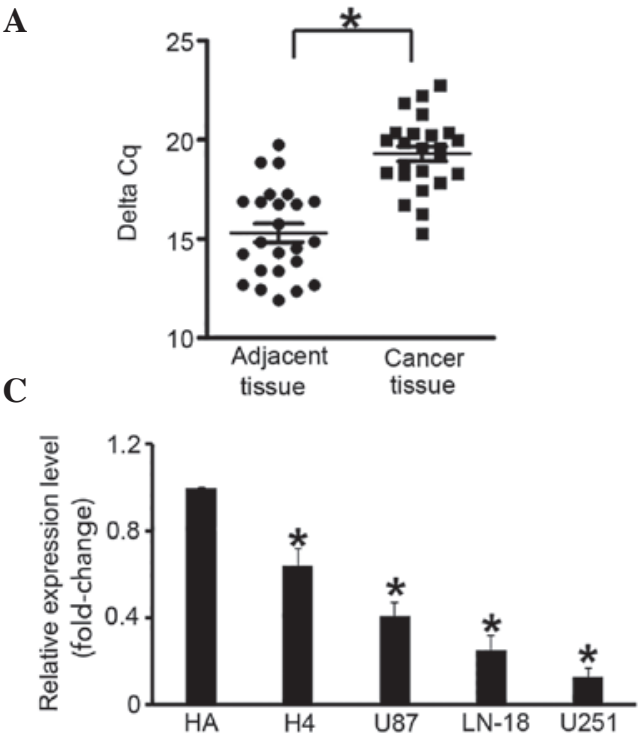

B

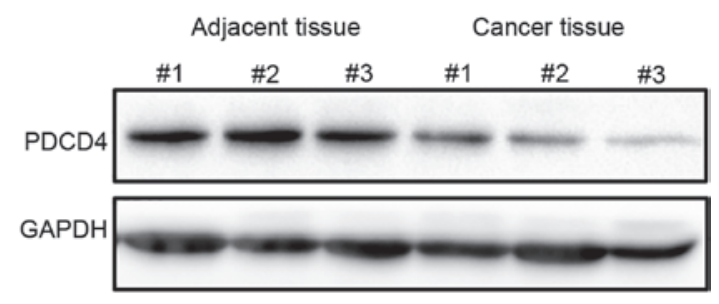

D

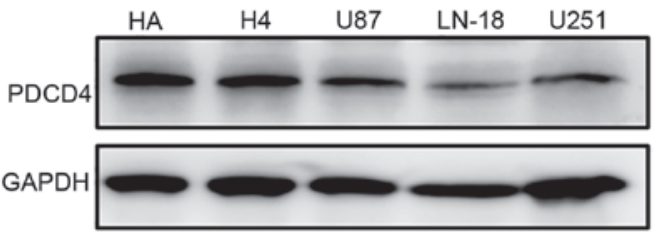

Figure 1. PDCD4 expression is downregulated in glioma cells. (A) $\triangle$ Cq values for PDCD4 RNA levels in 24 glioma tissue samples. (B) PDCD4 protein levels in 3 representative glioma tissue samples. (C) Relative PDCD4 RNA levels in the HA, H4, U87, LN-18 and U251 cells. Data represents the results of three independent experiments. (D) PDCD4 protein levels in the HA, H4, U87, LN-18 and U251 cells. "P<0.05 vs. negative control. PDCD4, programmed cell death protein 4; Cq, quantification cycle; GAPDH, glyceraldehyde 3-phosphate dehydrogenase.

with one-way analysis of variance. Statistical analyses were conducted using SPSS 13.0 software (SPSS, Inc., Chicago, IL, USA). $\mathrm{P}<0.05$ was considered to indicate a statistically significant difference.

\section{Results}

PDCD4 expression is downregulated in glioma cells. Human glioma tissue samples $(n=24)$ were analyzed to detect the change in expression of PDCD4 in glioma. RT-qPCR demonstrated that PDCD4 was significantly downregulated in glioma tissues (by $\sim 20 \%$ ), as compared with adjacent normal tissues ( $\mathrm{P}=0.034$; Fig. 1A), which was supported by western blot analysis (Fig. 1B). In a few samples, no PDCD4 expression was detected.

This experiment was repeated with glioma cell lines (U251, $\mathrm{LN}-18$, U87 and H4), and the human astrocyte HA cell line was used as the control. RT-qPCR and western blot analysis demonstrated that PDCD4 expression was suppressed in all glioma cell lines compared with the HA cells, and its expression was the lowest in the U251 cells (Fig. 1C and D).

PDCD4 inhibits cell growth and invasion in glioma cells. Next, the potential functions of PDCD4 in glioma were investigated. A lentivirus was constructed, Lenti-PDCD4, containing the full length PDCD4 cDNA, and PDCD4 was overexpressed in U251 cells by infection with Lenti-PDCD4. Western blot analysis indicated that PDCD4 was successfully overexpressed compared with the Lenti-Empty construct (Fig. 2A). CCK-8 assay was employed to determine whether PDCD4 affects the proliferation of glioma cells. Glioma cells infected with Lenti-PDCD4 exhibited a significantly lower proliferation rate than the control at 48 and $60 \mathrm{~h}$ following transfection $(\mathrm{P}<0.05$; Fig. $2 \mathrm{~B})$. In addition, Transwell migration assays were performed to verify invasive ability. The results demonstrated that PDCD4 overexpression resulted in a significant decrease in the invasion rate of U251 cells compared with the control ( $\mathrm{P}<0.05 ;$ Fig. $2 \mathrm{C})$. 
A

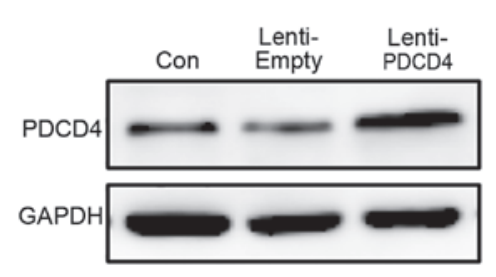

B

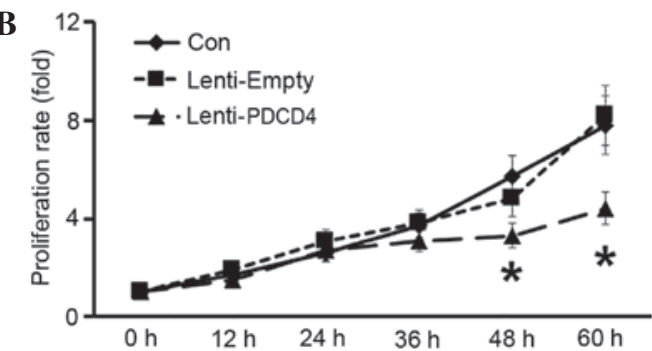

C

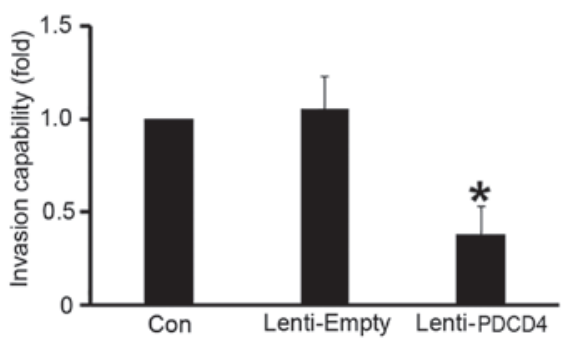

Figure 2. PDCD4 inhibits cell growth and invasion in glioma cells. (A) Expression level of PDCD4 in U251 cells infected with lentivirus overexpressing PDCD4 (Lenti-PDCD4). Lentivirus containing the empty vector (Lenti-Empty) was used as a negative control. (B) Cell counting kit-8 assay was performed on U251 cells overexpressing PDCD4. (C) Transwell analysis was performed to determine invasive capability and luciferase detection values for each cell type were compared. All experiments were repeated three times. ${ }^{*} \mathrm{P}<0.05$ vs. negative control. PDCD4, programmed cell death protein 4 ; GAPDH, glyceraldehyde 3-phosphate dehydrogenase; Con, control.

A

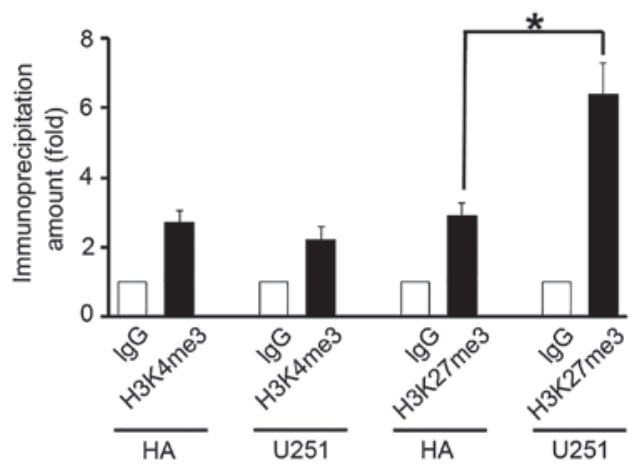

B

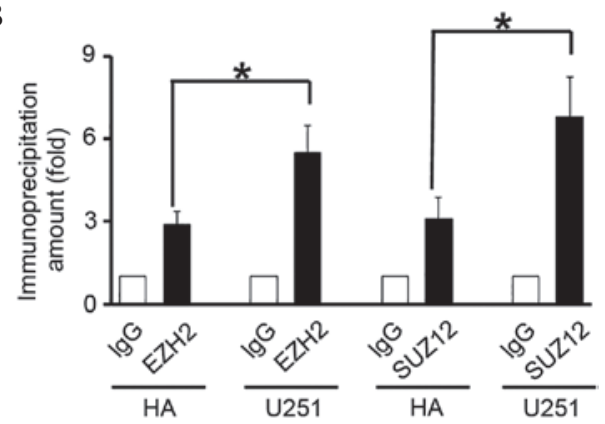

Figure 3. Histones of the PDCD4 promoter may be methylated by the polycomb repressive complex 2 complex. (A) ChIP analysis of $\mathrm{H} 3 \mathrm{~K} 4 \mathrm{me} 3$ and $\mathrm{H} 3 \mathrm{~K} 27 \mathrm{me} 3$ histone modification at the PDCD4 promoter in HA and U251 cells. (B) ChIP analysis of EZH2 and SUZ12 recruitment to the PDCD4 promoter in HA and U251 cells. All experiments were repeated three times. ${ }^{*} \mathrm{P}<0.05$ vs. negative control. PDCD4, programmed cell death protein 4 ; ChIP, chromatin immunoprecipitation; IgG, immunoglobulin G; H3K4me3, histone 3 lysine 4 trimethylation; H3K27me3, histone 3 lysine 27 trimethylation; EZH2, enhancer of zeste homolog 2; SUZ12, suppressor of zeste 12 .

Histones at the PDCD4 promoter may be methylated by the PRC2 complex. Next, mechanisms underlying PDCD4 downregulation in glioma were investigated. Epigenetic modifications, particularly methylation at specific histone sites, are important in gene expression. ChIP assays demonstrated that the level of $\mathrm{H} 3 \mathrm{~K} 27 \mathrm{me} 3$ at the PDCD4 promoter region increased significantly in the $\mathrm{U} 251$ cells, as compared wih the HA cells ( $\mathrm{P}=0.019$; Fig. $3 \mathrm{~A})$, thus favoring transcriptional silencing. Conversely, H3K4me3 exhibited little change between the HA and U251 cells ( $\mathrm{P}>0.05$; Fig. 3A). The levels of EZH2 and suppressor of zeste 12 (SUZ12), core components of the PRC2 complex, at the PDCD4 promoter region were significantly increased in the $\mathrm{U} 251$ cells, as compared with the HA cells $(\mathrm{P}<0.05$; Fig. 3B). These results indicated that the PRC2 complex was able to downregulate PDCD4 expression by increasing the level of H3K27me3 at its promoter.

HOTAIR is upregulated in glioma cells. The expression of HOTAIR was measured in human glioma tissue samples. RT-qPCR demonstrated that HOTAIR expression was significantly elevated (by $\sim 30$-fold) in glioma tissues, as compared with normal tissues ( $\mathrm{P}=0.039$; Fig. 4A). A similar trend was observed in the glioma cell lines, in which HOTAIR RNA levels were significantly elevated compared with the HA cells $(\mathrm{P}<0.05$; Fig. 4B). To investigate the function of HOTAIR, the gene was knocked down in U251 cells using siRNA, which significantly decreased its expression, as compared with the scramble RNA ( $\mathrm{P}<0.05$; Fig. 4C).

HOTAIR participates in the silencing of PDCD4 in glioma cells. The present study investigated how the expression of PDCD4 was silenced in glioma cells. It was hypothesized that HOTAIR may induce the recruitment of PRC2 to the PDCD4 promoter. Western blot analysis indicated that PDCD4 expression was upregulated when HOTAIR was knocked down in glioma cells (Fig. 5A). Histone modifications at the PDCD4 promoter were measured by ChIP assays. The results demonstrated that when HOTAIR was knocked down in glioma cells, the H3K27me3 level at the PDCD4 promoter was significantly reduced compared with the control $(\mathrm{P}=0.031$; Fig. 5B). Furthermore, the recruitment of EZH2 and SUZ12 to the PDCD4 promoter was measured, and the results indicated that the level of PRC2 components at the PDCD4 promoter was decreased in glioma cells following HOTAIR-knockdown compared with the control (Fig. 5C). These results suggest that the upregulation of HOTAIR results in PDCD4 silencing in glioma cells.

\section{Discussion}

Glioma is the most aggressive form of tumor located in the human brain, and despite advances in available therapies, glioma remains incurable (18). The tumors are particularly difficult to eradicate due to their highly invasive and metastatic 
A

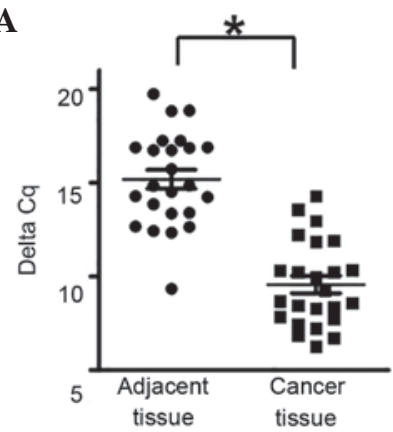

B

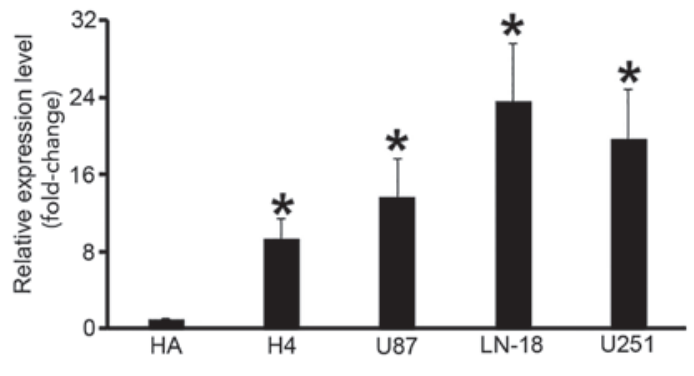

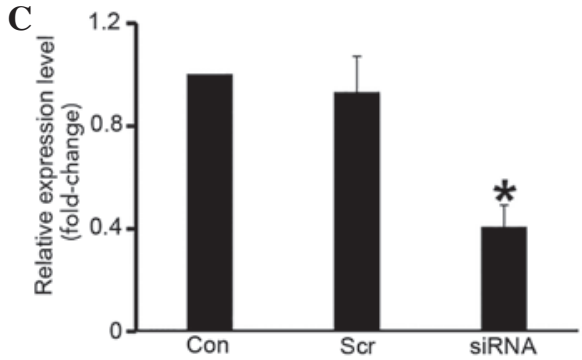

Figure 4. HOTAIR is upregulated in glioma cells. (A) $\triangle \mathrm{Cq}$ values for HOTAIR RNA levels in 24 glioma tissue samples. (B) HOTAIR RNA levels in HA, H4, U87, LN-18 and U251 cells. Data represents the results of three independent experiments. (C) Relative expression levels of HOTAIR in U251 cells treated with siRNA targeting HOTAIR. "P<0.05 vs. negative control. HOTAIR, homeobox transcript antisense RNA; Cq, quantification cycle; siRNA, small interfering RNA; Con, control; Scr, scramble.

A

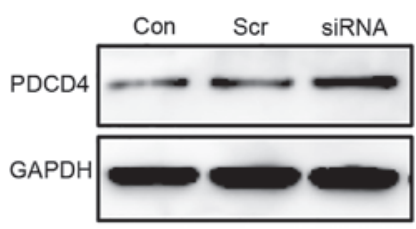

B

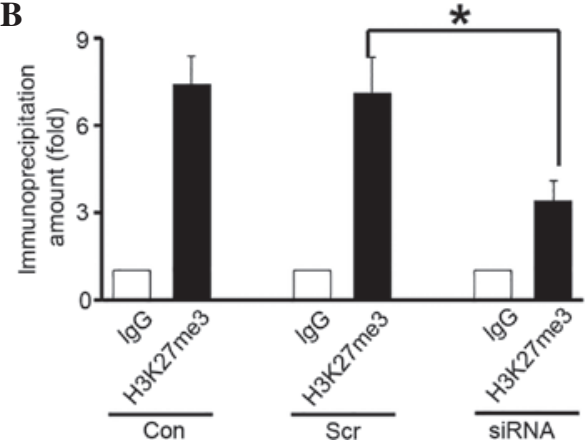

C

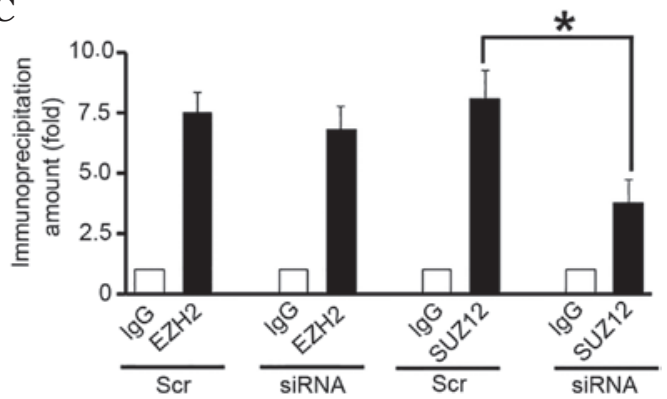

Figure 5. HOTAIR participates in the silencing of PDCD4 in glioma cells. (A) PDCD4 expression level in U251 cells treated with siRNA targeting HOTAIR. Scr RNA was used as the negative control. (B) ChIP analysis of H3K27me3 histone modification at the PDCD4 promoter in U251 cells treated with siRNA. (C) ChIP analysis of EZH2 and SUZ12 recruitment to the PDCD4 promoter in U251 cells treated with siRNA. All experiments were repeated three times. "P<0.05 vs. negative control. HOTAIR, homeobox transcript antisense RNA; PDCD4, programmed cell death protein 4; siRNA, small interfering RNA; Scr, scramble; ChIP, chromatin immunoprecipitation; H3K27me3, histone 3 lysine 27 trimethylation; EZH2, enhancer of zeste homolog 2; SUZ12, suppressor of zeste 12; Con, control.

capabilities (19). In the present study, it was demonstrated that PDCD4 expression was suppressed in glioma cells, which suggested that PDCD4 may participate in glioma tumorigenesis.

As a potential tumor suppressor, PDCD4 regulates the expression of a variety of proteins, including p21 (20), urokinase receptor (21), hematopoietic progenitor kinase 1 (22), ornithine decarboxylase (23), carbonic anhydrase II (24) and c-Jun N-terminal kinase/c-Jun/activator protein 1 (25). In glioma cells, the function of PDCD4 remains poorly understood. Liwak et al (26) reported that the loss of PDCD4 expression contributes to increased chemotherapy resistance in glioblastoma multiforme by derepressing B-cell lymphoma-extra large translation. Gaur et al (27) reported that PDCD4 downregulation by miRNA-21 promotes glioblastoma proliferation in vivo. In the current study, when PDCD4 was overexpressed in glioma cells, the proliferation rate and invasive capability significantly increased compared with the control. However, no information regarding the regulation of PDCD4 in glioma has been reported. The present study therefore proposes that PDCD4 regulation depends on alterations in histone modification at promoter region.

LncRNAs are generally defined as mRNA-like, non-protein coding transcripts that are $>200$ nucleotides in length $(28,29)$. Using the most advanced sequencing platforms and algorithms for assembling transcripts from deep RNA-sequencing reads, it is estimated that there are 20,000 distinct lncRNAs in humans (30). LncRNAs demonstrate unique profiles in different forms of human cancer, which serve as predictors of patient outcomes and reflect disease progression $(31,32)$. It was recently identified 
that lncRNAs function in a number of aspects of cell biology and may aid the development of tumors (33). HOTAIR, a well-studied lncRNA, has emerged as an important regulator of carcinogenesis and metastasis, and as a potential prognostic marker $(34,35)$. Therefore, an increasing amount of research has focused on determining its functions, in addition to identifying its target genes. The present study observed that the expression of HOTAIR was dramatically upregulated in glioma cells compared with normal human astrocyte cells.

Regarding the function of HOTAIR, previous studies identified a possible role for HOTAIR in cancer. HOTAIR interacts with PRC2, which increases the level of H3K27me3, and subsequently decreases the expression of various genes, particularly metastasis-suppressing genes $(36,37)$. Furthermore, the present study investigated the association between HOTAIR and PDCD4. The results demonstrated that the elevated expression of HOTAIR participated in PDCD4 regulation in a PRC2-dependent manner.

In conclusion, to the best of our knowledge, the current study investigated the association between the tumor suppressor PDCD4 and the lncRNA HOTAIR in glioma cells for the first time, with the results demonstrating that suppression of PDCD4 mediated by HOTAIR inhibits glioma cell proliferation and invasion in a PRC2-dependent manner. The results of the present study may aid the understanding of the detailed molecular mechanisms underlying glioma tumorigenesis, and support the notion that understanding the regulation of PDCD4 expression via HOTAIR intervention may contribute to the development of therapeutic strategies for the treatment of gliomas.

\section{References}

1. Morgan LL: The epidemiology of glioma in adults: A 'state of the science' review. Neuro-Oncol 17: 623-624, 2015.

2. Grauer OM, Wesseling P and Adema GJ: Immunotherapy of diffuse gliomas: Biological background, current status and future developments. Brain Pathol 19: 674-693, 2009.

3. Cloughesy TF, Cavenee WK and Mischel PS: Glioblastoma: From molecular pathology to targeted treatment. Annu Rev Pathol 9: 1-25, 2014

4. Gu JJ, Gao GZ and Zhang SM: miR-218 inhibits the migration and invasion of glioma U87 cells through the Slit2-Robo1 pathway. Oncol Lett 9: 1561-1566, 2015.

5. Cmarik JL, Min H, Hegamyer G, Zhan S, Kulesz-Martin M, Yoshinaga H, Matsuhashi S and Colburn NH: Differentially expressed protein Pdcd4 inhibits tumor promoter-induced neoplastic transformation. Proc Natl Acad Sci USA 96: 14037-14042, 1999

6. Lankat-Buttgereit B and Göke R: The tumour suppressor Pdcd4: Recent advances in the elucidation of function and regulation. Biol Cell 101: 309-317, 2009.

7. Gao F, Zhang P, Zhou C, Li J, Wang Q, Zhu F, Ma C, Sun W and Zhang L: Frequent loss of PDCD4 expression in human glioma: Possible role in the tumorigenesis of glioma. Oncol Rep 17: 123-128, 2007.

8. Chen Y, Knösel T, Kristiansen G, Pietas A, Garber ME, Matsuhashi S, Ozaki I and Petersen I: Loss of PDCD4 expression in human lung cancer correlates with tumour progression and prognosis. J Pathol 200: 640-646, 2003

9. Li Y, Li W, Yang Y, Lu Y, He C, Hu G, Liu H, Chen J, He J and $\mathrm{Yu}$ H: MicroRNA-21 targets LRRFIP1 and contributes to VM-26 resistance in glioblastoma multiforme. Brain Res 1286: 13-18, 2009

10. Wei NA, Liu SS, Leung TH, Tam KF, Liao XY, Cheung AN, Chan KK and Ngan HY: Loss of programmed cell death 4 (Pdcd4) associates with the progression of ovarian cancer. Mol Cancer 8: 70, 2009.
11. Liwak U, Jordan L E, Von-Holt S D, Singh P, Hanson JE, Lorimer IA, Roncaroli F and Holcik M: Loss of PDCD4 contributes to enhanced chemoresistance in Glioblastoma multiforme through de-repression of Bcl-xL translation. Oncotarget 4: 1365-1372, 2013.

12. Gao F, Wang X, Zhu F, Wang Q, Zhang X, Guo C, Zhou C, Ma C, Sun W, Zhang Y, et al: PDCD4 gene silencing in gliomas is associated with $5^{\prime} \mathrm{CpG}$ island methylation and unfavourable prognosis. J Cell Mol Med 13: 4257-4267, 2009

13. Chen Y, Liu W, Chao T, Zhang Y, Yan X, Gong Y, Qiang B, Yuan J, Sun M and Peng X: MicroRNA-21 down-regulates the expression of tumor suppressor PDCD4 in human glioblastoma cell T98 G. Cancer Lett 272: 197-205, 2008.

14. Mercer TR, Dinger ME and Mattick JS: Long non-coding RNAs: Insights into functions. Nat Rev Genet 10: 155-159, 2009.

15. Zhang J, Zhang A, Wang Y, Liu N, You Y, Kang C and Pu P: New insights into the roles of ncRNA in the STAT3 pathway. Future Oncol 8: 723-730, 2012.

16. Zhang JX, Han L, Bao ZS, Wang YY, Chen LY, Yan W, Yu SZ, Pu PY, Liu N, You YP, et al: HOTAIR, a cell cycle-associated long noncoding RNA and a strong predictor of survival, is preferentially expressed in classical and mesenchymal glioma. Neuro Oncol 15: 1595-1603, 2013.

17. Livak KJ and Schmittgen TD: Analysis of relative gene expression data using real time quantitative PCR and the 2( Delta Delta C(T)) Method. Methods 25: 402 408, 2001.)

18. Hu Y, Gao H, Vo C, Ke C, Pan F, Yu L, Siegel E, Hess KR, Linskey ME and Zhou YH: Anti-EGFR function of EFEMP1 in glioma cells and patient prognosis. Oncoscience 1: 205-215, 2014.

19. Wang XP, Deng XL and Li LY: MicroRNA-584 functions as a tumor suppressor and targets PTTG1IP in glioma. Int J Clin Exp Pathol 7: 8573-8582, 2014.

20. Göke R, Barth P, Schmidt A, Samans B and Lankat-Buttgereit B: Programmed cell death protein 4 suppresses CDK1/cdc2 via induction of p21(Waf1/Cip1). Am J Physiol Cell Physiol 287: C1541-C1546, 2004.

21. Leupold JH, Yang HS, Colburn NH, Asangani I, Post S and Allgayer H: Tumor suppressor Pded4 inhibits invasion/intravasation and regulates urokinase receptor (u-PAR) gene expression via Sp-transcription factors. Oncogene 26: 4550-4562, 2007.

22. Yang HS, Matthews CP, Clair T, Wang Q, Baker AR, Li CC, Tan TH and Colburn NH: Tumorigenesis suppressor Pdcd4 down-regulates mitogen-activated protein kinase kinase kinase kinase 1 expression to suppress colon carcinoma cell invasion. Mol Cell Biol 26: 1297-1306, 2006.

23. Jansen AP, Camalier CE and Colburn NH: Epidermal expression of the translation inhibitor programmed cell death 4 suppresses tumorigenesis. Cancer Res 65: 6034-6041, 2005.

24. Lankat-Buttgereit B, Gregel C, Knolle A, Hasilik A, Arnold R and Göke R: Pdcd4 inhibits growth of tumor cells by suppression of carbonic anhydrase type II. Mol Cell Endocrinol 214: 149-153, 2004.

25. Bitomsky N, Böhm M and Klempnauer KH: Transformation suppressor protein Pdcd4 interferes with JNK-mediated phosphorylation of c-Jun and recruitment of the coactivator p300 by c-Jun. Oncogene 23: 7484-7493, 2004.

26. Liwak U, Jordan LE, Von-Holt SD, Singh P, Hanson JE, Lorimer IA, Roncaroli F and Holcik M: Loss of PDCD4 contributes to enhanced chemoresistance in Glioblastoma multiforme through de-repression of Bcl-xL translation. Oncotarget 4: 1365-1372, 2013.

27. Gaur AB, Holbeck SL, Colburn NH and Israel MA: Downregulation of Pdcd 4 by mir-21 facilitates glioblastoma proliferation in vivo. Neuro Oncol 13: 580-590, 2011.

28. Ernst $\mathrm{C}$ and Morton CC: Identification and function of long non-coding RNA. Front Cell Neurosci 7: 168, 2013.

29. Ponting CP, Oliver PL and Reik W: Evolution and functions of long noncoding RNAs. Cell 136: 629-641, 2009.

30. Moran VA, Perera RJ and Khalil AM: Emerging functional and mechanistic paradigms of mammalian long non-coding RNAs. Nucleic Acids Res 40: 6391-6400, 2012.

31. Wang GY, Zhu YY and Zhang YQ: The functional role of long non-coding RNA in digestive system carcinomas. Bull Cancer 101: E27-E31, 2014.

32. Bhan A and Mandal SS: Long noncoding RNAs: Emerging stars in gene regulation, epigenetics and human disease. ChemMedChem 9: 1932-1956, 2014. 
33. Liu MX, Chen X, Chen G, Cui QH and Yan GY: A computational framework to infer human disease-associated long noncoding RNAs. PLoS One 9: e84408, 2014.

34. Wan Y and Chang HY: HOTAIR: Flight of noncoding RNAs in cancer metastasis. Cell Cycle 9: 3391-3392, 2010.

35. Lv DW, Ge P, Zhang M, Cheng ZW, Li XH and Yan YM: Integrative network analysis of the signaling cascades in seedling leaves of bread wheat by large-scale phosphoproteomic profiling. J Proteome Res 13: 2381-2395, 2014.
36. Gupta RA, Shah N, Wang KC, Kim J, Horlings HM, Wong DJ, Tsai MC, Hung T, Argani P, Rinn JL, et al: Long non-coding RNA HOTAIR reprograms chromatin state to promote cancer metastasis. Nature 464: 1071-1076, 2010.

37. Li L, Liu B, Wapinski OL, Tsai MC, Qu K, Zhang J, Carlson JC, Lin M, Fang F, Gupta RA, et al: Targeted disruption of Hotair leads to homeotic transformation and gene derepression. Cell Rep 5: 3-12, 2013. 